\title{
PENGARUH UKURAN POTONG TERHADAP ATRIBUT SENSORI DENGAN PENGUJIAN ALAT E-TOUNG PADA TEH SAWO ( Manilkara zapota)
}

\author{
Resti Arbaiah \\ Program Teknologi Industri Pangan- Fakultas Teknologi Industri Pertanian, \\ E-mail : restiarbaiah@gmail.com
}

\begin{abstract}
Abstrak
Penelitian teh sawo bertujuan untuk mengetahui atribut sensori dengan menggunakan alat e-tongue . Metode penelitian ini yaitu eksperimental deskriptif. Hasil penelitian sensori alat e-tongue dalam variasi pengirisin pada sensori teh sawo nilai asam, pahit, sepat, gurih, dan after taste tidak jauh berbeda yaitu 0,04- 0,63 mmol. Kadar air pengeringan (3mm, $5 \mathrm{~mm}$, dan $8 \mathrm{~mm}$ ) dengan nilai kadar air 3,63\%, 4,47\% dan 6,36\%. Nilai rendemen yaitu 3mm, 20,35\%; 5mm, 21,79\% dan $8 \mathrm{~mm}, 22,49 \%$.
\end{abstract}

Kata Kunci : Teh, E-Tongue, Sensori

\section{Pendahuluan}

Teh telah dikenal secara luas di berbagai negara dan menjadi minuman paling banyak dikonsumsi manusia dewasa setelah air (Sunyoto, 2018). Hal ini disebabkan karena teh memiliki aroma yang khas dan rasa yang disukai. Selain itu, karena zat-zat yang terkandung dalam teh memiliki banyak manfaat terutama sebagai antioksidan dan antikanker (Sunyoto, 2018).

Awalnya, sebutan teh hanya ditujukan pada hasil infusi tanaman Camellia sinensis L. Kuntze, seperti teh hitam, teh hijau, dan teh oolong. Adapun jenis teh selain dari Camellia sinensis adalah teh herbal. Teh herbal tidak mengandung kafein, sehingga cocok digunakan sebagai detoksifikasi tubuh (Wahyuningsih, 2011). Akhir-akhir ini semakin berkembang penelitian mengenai pembuatan teh berbahan dasar tanaman herbal. Bahan-bahan tersebut berasal dari daun kering, biji, akar, batang, bunga, kulit, buah kering (Inti K, 2008).

Teh herbal merupakan salah satu minuman dalam bentuk tunggal atau campuran teh dan tanaman herbal yang memiliki khasiat dalam membantu pengobatan suatu penyakit atau sebagai minuman penyegar tubuh. Khasiat yang dimiliki setiap teh herbal berbeda-beda $t$ ergantung bahan baku yang digunakan (Hambali et al. 2006).

Saat dilakukannya pemanenan buah sawo terdapat buah sawo muda yang ikut terambil. Ketika dilakukannya pensortiran oleh petani terdapat buah sawo yang tidak digunakan lagi sehingga langsung dilakukan pembuangan karena buah sawo tersebut berukuran masih sangat kecil yaitu berdiameter $2 \mathrm{~cm}$, berwarna hijau kecoklatan sehingga memiliki kualitas off grade karena tidak dapat dikonsumsi langsung dalam keadaan segar, jika dilakukan pemeramanpun rasa yang dihasilkan tidak akan semanis buah yang diameter 4,7$4,9 \mathrm{~cm}$ sebagai buah yang layak untuk dilakukan penjualan kepada produsen.

Maka dilakukannya pemanfaatan bahan baku buah sawo off grade sebagai salah satu alternatif pembuatan teh. Dimana buah sawo off grade memiliki kandungan tanin yang dapat berfungsi sebagai alternatif obat diare alami (Dalimartha, 2008).
Berdasarkan uraian di atas peneliti memanfaatkan buah sawo off grade sebagai bahan baku dalam pembuatan teh. Dimana betujuan untuk mengetahui atribut sensori dengan alat electronik tongue pada teh sawo.

\section{Metode Penelitian}

Metode yang digunakan dalam penelitian ini adalah Eksperimental deskriptif dengan menggunakan buah sawo dari Cipatujah Tasikmalaya, Jawa Barat sebagai bahan yang diamati. Penelitian ini dilakukan melalui percobaan secara langsung dengan variasi ukuran pengirisan yaitu $3 \mathrm{~mm}, 5 \mathrm{~mm}$ dan $8 \mathrm{~mm}$ menggunakan food dehydrator dengan suhu 700C selama 21 jam. Data yang diperoleh akan dianalisa secara deskriptif presentasi grafik dan tabular untuk mengetahui besar rendemen, kadar air dengan menggunakan oven dan organoleptik menggunakan alat sensori e-tongue.

Tahap penelitian ini adalah proses pengolahan teh buah sawo dilakukan tiga variasi pengirisan yaitu $3 \mathrm{~mm}$, $5 \mathrm{~mm}$, dan $8 \mathrm{~mm}$ selanjutnya dilakukan pencucian kemudian pengeringan, penghancuran menggunakan grinder, pengayakan menggunakan 30 mesh agar serbuk yang dihasilkan seragam. Pada proses ini, bubuk buah sawo dilakukan penyeduhan dengan suhu 850C dengan perbandingan 1:10 (w/v) selama 8 menit, penyaringan agar dihasilkan filtrat teh buah sawo. Filtrat teh buah sawo dimasukkan ke dalam alat e- tongue untuk dilakukan pengukuran kualitas rasa berdasrkan sensitivitas, selektivitas, intensitas, dan interaksinya.

\section{Hasil dan Pembahasan}

\section{Kadar Air}

Kadar air merupakan salah satu parameter penting untuk produk berbentuk bubuk karena akan mempengaruhi stabilitas dan penyimpanan produk. Kadar air yang terlalu tinggi akan membuat daya simpan produk menjadi rendah karena mudah menjadi media pertumbuhan jamur. Kadar air hasil pengeringan dengan tiga variasi pengirisan $(3 \mathrm{~mm}, 5 \mathrm{~mm}$, dan $8 \mathrm{~mm})$ terdapat pada Gambar 1, dengan nilai kadar air 3,63\%, 4, $47 \%$, dan $6,36 \%$. 


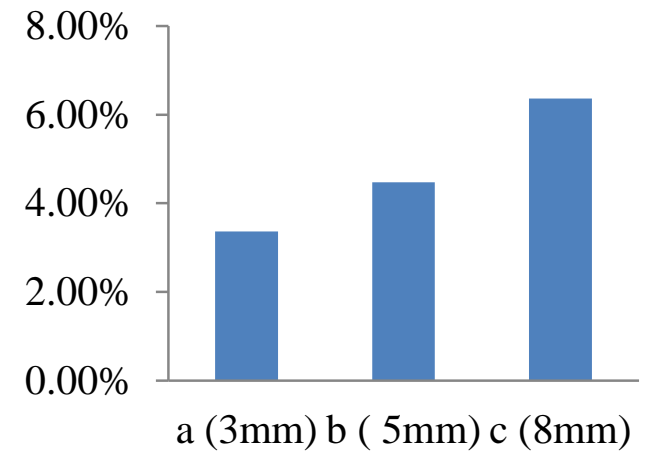

Gambar 1. Grafik Perubahan Kadar Teh Sawo

Pengaruh ukuran pengirisan terhadap pengeringan yaitu semakin kecil ukuran pemotongan yang dilakukan maka semakin kecil kadar air yang dihasilkan. Hal ini dikarenakan ukuran pengirisan $3 \mathrm{~mm}$ sangat tipis maka kadar air yang terdap di dalam bahan akan semakin cepat menguap dan semakin tebal $8 \mathrm{~mm}$ ukuran pengirisan maka semakin lamat terjadinya proses penguapan. Luas permukaan bahan mempengaruhi terjadinya perbedaan selisih kadar air yang dihasilkan (Prasetyo dan Inoriah, 2013). Presentase kadar air hasil penelitian sudah sesuai dengan standar mutu teh kering yang memiliki kadar air maksimal $8 \%$ berdasrkan SNI (Standar Nasional Indonesia).

\section{Rendemen}

Rendemen bubuk teh sawo dihitung berdasrkan massa awal sawo berbanding dengan massa akhir pengeringan sawo. Nilai rendemen bubuk teh sawo berdasrkan variasi ukuran pengirisan yaitu $3 \mathrm{~mm}, 20$, $35 \%$; 5mm, 21, 79\%; dan 8 mm, 22,49\%. Berikut hasil lengkapnya terdapat pada Gambar 2.

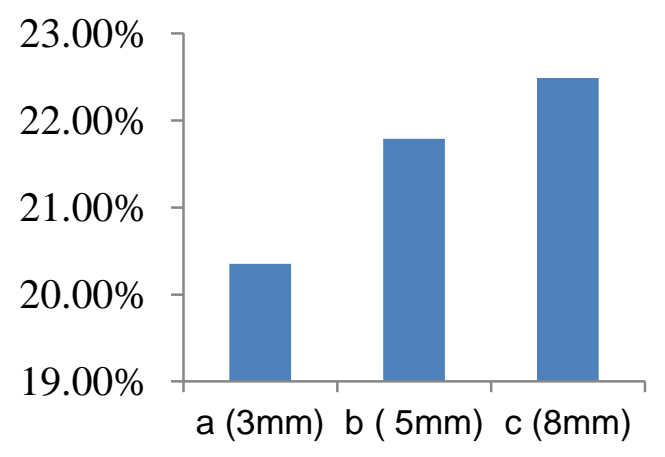

Gambar 2. Grafik Rendemen Bubuk Teh Sawo

Nilai rendemen bubuk teh sawo dipengaruhi oleh beberapa faktor salah satunya ukuran pengirisan pada proses pengeringan. Dimana pada ukuran pengirisan $8 \mathrm{~mm}$ rendemen bubuk teh sawo mengalami peningkatan dari ukuran pengirisan $5 \mathrm{~mm}$ dan $3 \mathrm{~mm}$. Lapisan-lapisan bahan yang tipis dapat mengurangi jarak panas yang ditempuh sampai ke pusat bahan pangan sehingga penguapan air dari bahan akan lebih cepat (Simamora, 2014).

\section{Sensori Oleh Alat E-Tongue}

Electronic tongue mengevaluasi kualitas rasa pada produk pangan bukan dari analisis kandungan kimianya, melainkan diamati sensitivitas, selektivitas, intensitas, dan interaksinya; di mana gabungan dari keempat faktor tersebut membentuk respon basic taste (Toko, 2013).

Sensori pada teh sawo dengan penggunaan alat etongue dengan hasil yang didapatkan berupa nilai kuantitatif. Sinyal yang diinput kemudian disesuaikan oleh larutan penyangga dan kemudian sinyalnya dikuatkan dengan amplifier agar dapat terbaca oleh sistem electronic tongue yang terdiri atas polianilin oligomer dan polipirol yang dapat membedakan kelima jenis rasa (basic taste), yaitu larutan asin, manis, pahit, asam, dan gurih (umami). Pengujian terhadap kualitas dari setiap jenis rasa menggunakan sensor elektronik yang terdiri dari campuran membran dioktil fosfat dan trioktil metil amonium klorida dengan lima sampel uji berbeda (Toko, 2013). Berikut hasil sensori yang diperoleh dapat dilihat pada Tabel 1.

Tabel 1. Sensori Teh Sawo dengan Alat E-Tongue

\begin{tabular}{|c|c|c|c|c|c|}
\hline $\begin{array}{c}\text { Ukuran } \\
\text { Irisan }\end{array}$ & Asam & Pahit & Sepat & Gurih & $\begin{array}{c}\text { After } \\
\text { Taste }\end{array}$ \\
\hline $3 \mathrm{~mm}$ & $\begin{array}{c}- \\
19,11\end{array}$ & 5,37 & 3,77 & 11,73 & 1,04 \\
\hline $5 \mathrm{~mm}$ & $\begin{array}{c}- \\
18,56\end{array}$ & 5,21 & 3,73 & 11,12 & 1,12 \\
\hline $8 \mathrm{~mm}$ & $\begin{array}{c}- \\
19,19\end{array}$ & 5,12 & 3,77 & 11,26 & 1,08 \\
\hline
\end{tabular}

(Sumber : Dokumentasi Pribadi)

Berdasarkan sensori yang dihasilkan pada teh sawo dengan penggunaan alat $e$ - tongue nilai asam, pahit, sepat, gurih, dan after taste tidak jauh berbeda yaitu 0,04- 0,63.

Ketika dua variabel atau atribut sensori berada jauh dari pusat lalu dekat satu sama lain maka kuadran yang sama memiliki korelasi positif satu sama lain sedangkan atribut yang arahnya sling bertolak belakang memiliki korelasi negatif (Addinsoft, 2017). Berikut atribut sensori teh sawo dapat dilihat pada Gambar 3.

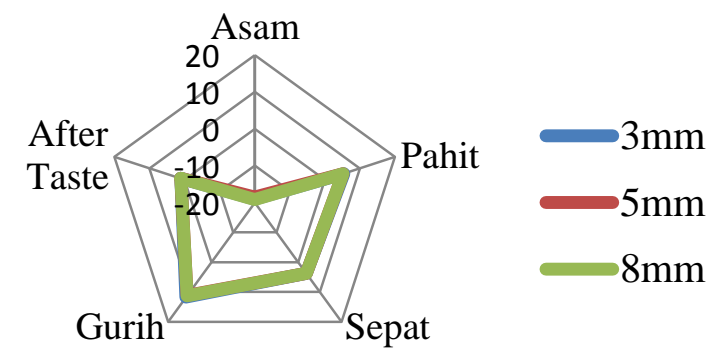

Gambar 3. Sensori Rasa Teh Sawo 
Rasa teh sangat dipengaruhi oleh komponen kimia di dalamnya, seperti polifenol, kafein, asam organik, dan terpen volatil (Borse et al. 2002). Karakteristik rasa dari teh adalah campuran dari rasa pahiit, sepat, umami, manis, dan sedikit asam. Senyawa yang berperan dalam karakteristik rasa teh adalah polifenol, asam amino, dan kafein (Senanayake, 2013).

Berdasarkan hasil penelitian, dapat diambil kesimpulan bahwa kadar air yang paling baik yaitu 3, $63 \%$ pada perlakuan ukuran pengirisan $3 \mathrm{~mm}$. Sedangkan untuk rendemen pada perlakuan ukuran pengirisan $8 \mathrm{~mm}$ menghasilkan nilai tertinggi yaitu sebesar 22, 49\%. Kemudian pada atribut sensori dengan penggunaan alat e-tongue pada perlakuan ukuran pengirisan $3 \mathrm{~mm}$ yang paling mendominasi dari ke lima jenis rasa atribut sensori secara kuantitatif.

\section{Daftar Pustaka}

1. Anita, L. D., H. Dwiyani, dan D. Erfan. 2010. Pengembangan Tepung Ganyong Sebagai Pengganti Tepung Terigu di Indonesia. Program Kreativitas Mahasiswa. IPB : Bogor.

2. [BSN] Badan Standarisasi Nasional. 2013. Syarat Mutu Minuman Serbuk Tradisional SNI 014320-1996. Badan Standarisasi Nasional, Jakarta.

3. Addinsoft. 2017. Prisipal Component Analysis (PCA) in Axcel.diakses pada Januari 2019. Tersedia pada: http://www.help.xlstat.com

4. Borse BB, Rao LJM, Nagalakshmi S, dan Krishnamurthy N. 2002. Fingerprint of black teas from India : Identification the regio-specific characteristic. Food Chemistry. 79: 419-424.

5. Dalimartha, Setiawan. 2008. Atlas Tumbuhan Obat Indonesia Jilid I. Trubus Agriwidya, Jakarta.

6. Hambali, E., M.Z. Nasution dan E. Herliana. 2006. Membuat Aneka Herbal Tea. Penebar Swadaya, Jakarta.

7. Inti, K. 2008. Teh Herba Minuman Berkhasiat Pemulih Kesehatan. Gramedia Pustaka Utama. Jakarta.

8. Prasetyo dan Inoriah, E. 2013. Pengelolaan Budidaya Tanaman Obat-obatan (Bahan Simplisia).Badan Penerbitan Fakultas Pertanian UNIB. Bengkulu.

9. Senanayake N. 2013. Green tea extract: chemistry, antioxidant properties and food aplications - A review. Journal of Functional Foods.doi: 10.1016/j.jff.2013.08.011.

10. Simamora, Aprilia SKY. 2014. Pengaruh Lama Pengeringan Kentang dan Perbandingan Tepung Terigu dan Tepung Kentang Terhadap Mutu Cookies Kentang. Medan: Universitas Sumatera Utara

11. Sunyoto, Marleen. 2018. Amazing tea. Bitread Publishing. Bandung.

12. Toko, Kiyoshi. 2013. Biochemical Sensors : Mimicking Gustatory and Olfactory Sensors. Pan Stanford Publishing, United States.
13. Wahyuningsih, M.S.H. 2011. Deskriptif Penelitian Dasar Herbal Medicine. Bagian Farmasi

Kedokteran, Fakultas Kedokteran Universitas Gajah Mada Yogyakarta. 